\title{
EARLY MARRIAGE; A ROOT OF CURRENT PHYSIOLOGICAL AND PSYCHOSOCIAL HEALTH BURDENS
}

\author{
Sadaf Ahmed ${ }^{1 \& 2}$, Amna Khan ${ }^{1}$ Saima Khan $^{1}$ \& Shamoon Noushad ${ }^{1}$ \\ 1. Advance Educational Institute \& Research Centre. \\ 2. University of Karachi \\ Corresponding author email: optimistminds@gmail.com
}

\begin{abstract}
It is confirmed that early marriage and early childbirth leads to higher rates of adolescent fertility and pregnancy related complications. According to UNICEF (1994) unfortunately the mortality rate of the married girls aged between 15-19 years is twice as compare to the girls who marry after the age of 20 years. As their bodies are immature that's why their health is affected by giving birth to a child. Millions of children are affected by the tradition of early marriage at is being practiced and widespread in many regions of South Asia. Early marriage is also called as child marriage that is marriage below the age of 18 when girls are too weak to shoulder their responsibilities physiologically, psychologically and socially. Early married females are more prone to diseases like HIV/AIDS and obstetrics obstacles. They are also affected psychologically and they may become victim of depression, anxiety and other mood disorders. An observational study was conducted between married and unmarried female to know their perspective about getting married early and to highlight whether it is a positive response according to them. Results showed that in relation to unmarried girls the married females were also not in favor of getting married early as they are equally invaded by health problems. Mental distress and depressive symptoms are more common in married females. Girls prefer doctors for concerning their reproductive health problems while girls can also concerned their mothers but they are in minority. Many health consequences are being reported by early married females and they were hesitated to share them with their in laws. Most of them approached lady doctors whereas few were relying on their mothers for their problems to be solved. Marriages below the age of 18 is not helping the females infract its demolishing their self esteem, their will to study and their physiological well being also.
\end{abstract}

\section{KEYWORDS}

Physiology, Psychosocial, Early marriage, Health, Early childbirth

\section{INTRODUCTION}

Throughout the world in different countries and regions the phenomenon of early marriage is not new as it has been in practice from generations to generation. Young girls are married when they are still children and hence they are forced to go through the difficulties and consequences of early pregnancies and other heavy responsibilities. This tradition of early marriage is seen in many south Asian countries like Nepal, Bangladesh, Afghanistan, Iran, Pakistan, India and many others. Early marriage of young females not only compromise their maturity, reproductive health and also counts for the consequences of early pregnancy and social seclusion. Beside these consequences these young girls are put under pressure of heavy domestic chores, reduced life choices, withdrawal from education and to exhibit fertility.

Early marriage as defined by UNICEF is to carry out marriage before age 18. Parents engaging their young daughters in marriage while they are still children are of hope that marriage will profit them economically and it is taken as a 'protection' for their daughters also. The marriage affects boys also but its impact on girls is far greater as compared to boys (UNICEF, 2005). Instead of being viewed as child or teenager, girls are considered as social customs exclusively as wives or mothers. In many countries the legal age of marriage is set up to 18 years. According to (DHS) demographic and health survey data $62 \%$ of females are married before they enter 20th year of their age. In countries like United States girls are even married as early at the age of 14 or 15 with the approval of their parents. Glancing globally, there are more than 15 million girls between the ages 15-19 who are married and bearing the burdens of domestic pressures, risks associated with sexual activity along with early pregnancy. The rate of early marriages is high in West Africa and higher in the regions of South Asia and central Africa (Walker, 2012). In South Asia the rate of marriage at young age is very high for instance in Bangladesh it is $65 \%, 48 \%$ in India, 54\% in Afghanistan, 7\% in Nepal and 14\% in Sri Lanka. (Mathur, 2003). In 2005 more than $48 \%$ nearly 10 million girls were married in South Asia before the age of 18. In Pakistan 13\% of girls are reported who were married between ages 15-19. According to UNICEF report (2003) girls who marry in teenage do not develop properly; physically and psychologically also they don't have access to education and are more prone to diseases arising from pregnancies and isolation. Most of the causes as told by the parents are underpinning the economical reason. Historically there were two main encouraging reasons for attempting the practice of early marriages; one of the reasons reveals that early marriage was thought important to maximize the chances of fertility. Moreover parents were afraid of sexual violence and exposure to sexual abuse, in many countries this marriage happens for the sake of economical, political alliances. Peeping at the consequences of early marriage the outcome of such activity is far greater than its impact on the child itself. Girls are forced to marry a person much elder than their own age and are put under the piles of domestic chores and responsibilities; and they give birth in their early childhood which is one of the reason that offspring born in such conditions is vulnerable to illness and death as mothers are too young and unaware of the looking after strategies. Early marriage is linked with poor social, physiological and psychological outcomes of the females as they have compact schooling, lower social status and also suffer higher rates of maternal mortality as their bodies are too immature to give birth. Early marriage means early sexual activity which increases the ratios of unwanted pregnancies and hence leading towards frequent 
abortions, HIV and other sexually transmitted disease (Mathur, 2003; Clark, 2004 \& Jacubowski, 2008). Underdeveloped physiology, lack of information, low self esteem and less awareness is leading young females to the high risk of maternal mortality and morbidity as compared to the females who are married after the age of 20. Physiological aggression from any of the partner may lead to psychological aggression making the relation between the two person worst which for sure affects the girl first as she is in her teens and male is mature. Such violent actions may affect the person with traumatic stress, depression, mood changes, anxiety and lack of confidence (Murphy, 1989). Health problems related to pregnancies are high and are found to be the root of obstetric labor, obstetric fistula and other complications. If the newborns survive it may have low birth weight and the female itself may prone to anemia, and due to poor developed body, large number of child bearing years there are more chances of miscarriages, heart diseases, low body weight, malnutrition, atherosclerotic risk and hormonal imbalances. Girls aged between 10-14 are five times more likely to die in pregnancies as compared to other females married in appropriate age (Ahmed, 2013; Kebede, 2007 \& Gallo, 2003). Such events occurring in a girl's life may bring up some changes in physical and psychological behaviors which results in mental distress, depression and other unexplained gynecologic symptoms. (Murphy, 2003). From many studies it is been observed that early marriage not only exploit women's physical well being but it also affects their mental peace and if not taken care of, these females may tend to attempt suicide. Marriage at early age appear fascinating to such teenagers as they think of love and good care but they do not know the responsibilities which they have to shoulder after marriage; often girls are abandoned to work load and bad family approach towards them. Marriage at young age is not supposed favorable to girl's protection and other economic reasons as teenage is for education, maturity, grooming oneself and an age for learning various life experiences. Quality education, moral support and family ethics can lend a great helping hand for such girls to be aware of the health consequences which can make them eligible to deal better in future (Ahmed, 2013).

\section{METHODOLOGY}

Cross sectional observational study was done on a designed questionnaire to evidence the demographic data and to know the level of physiological and psychosocial health burdens faced by single as well as married girls and to evaluate their views on education, parental support, reproductive health and marital age. The data was collected from 100 girls aged between 13- 35. Girls married before age of 20 were also included for comparison to conclude their views regarding health and psychological burdens. SPSS version 7 is used for the computation of result.

\section{RESULTS}

Graphical data shows that early marriage have caused many health problems around $87.5 \%$ of females were invaded by them where as 75.57 single girls also agreed to the opinion that getting married at early age causes health complications.

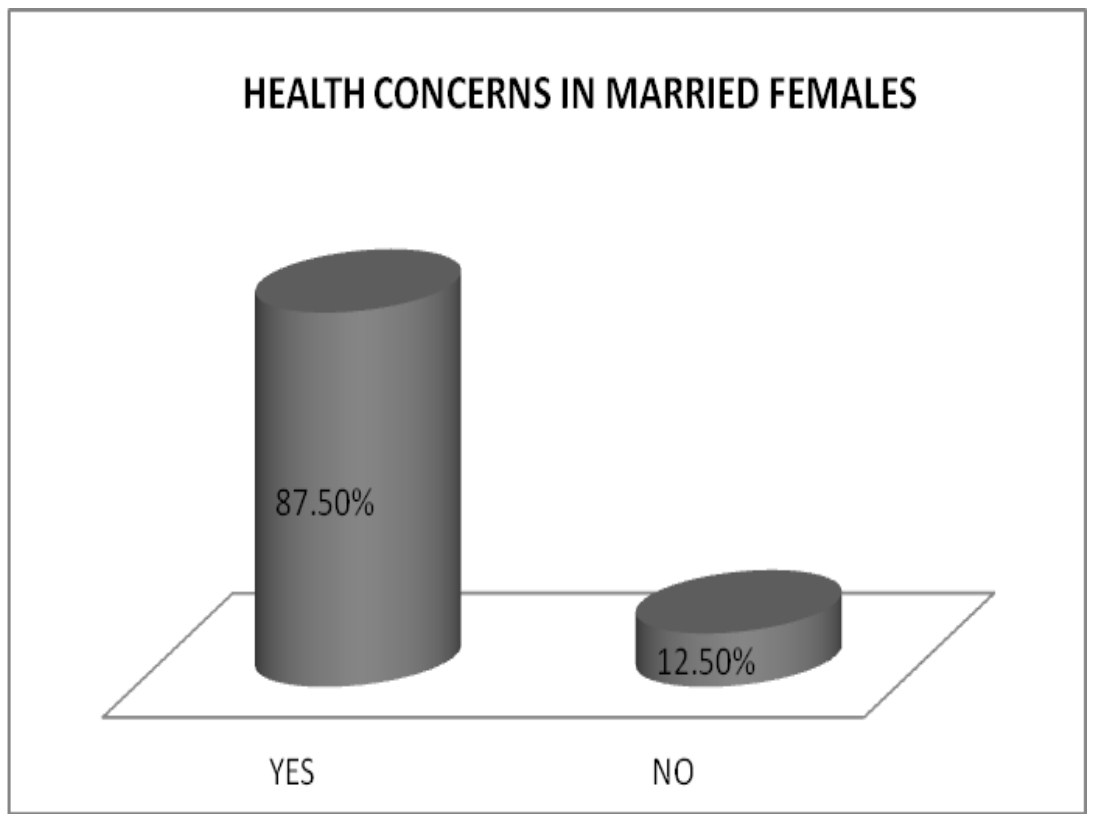

Fig. 1 shows \%age of married females in relation to health concerns as consequences of early marriage. 


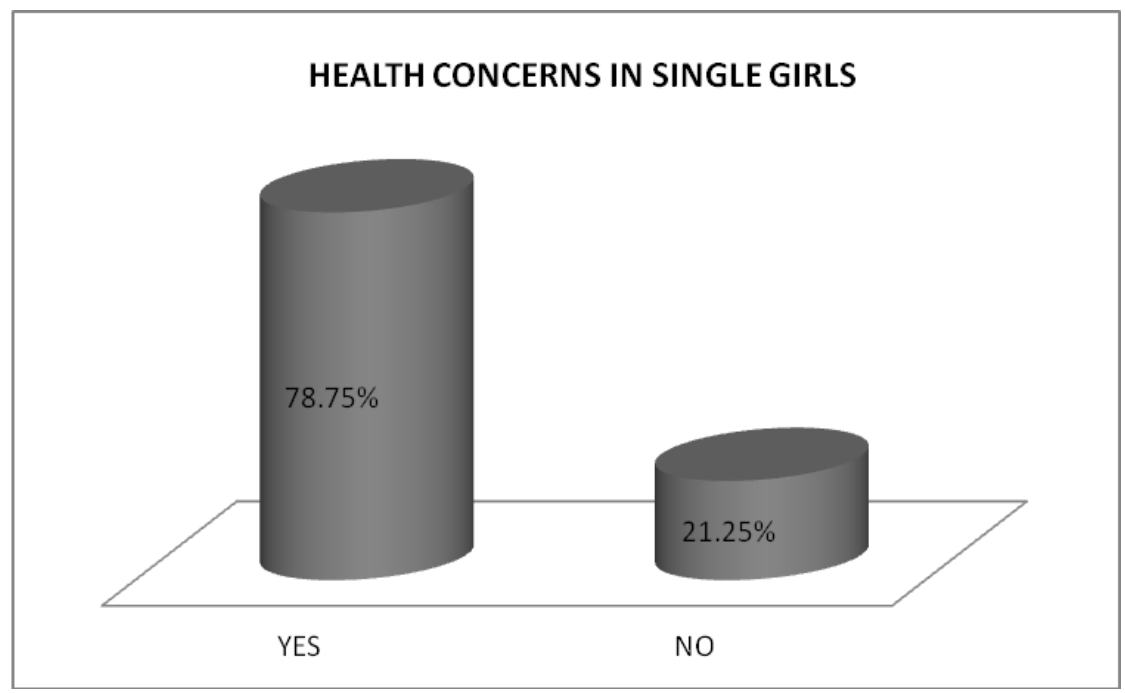

Fig\# 2 shows \%age of single girls in relation to health concerns after early marriages

\section{DISCUSSION}

Our study reveals that in developing world there remains a very high incidence of early marriage, though in some countries from the past few decades there is a decline but on the other hand in many countries the ratio increased (Santhya, 2010). Further we have found that women who marry in early teens are hit by disadvantages of education, health, independence and physical protection. In most of the societies, marriage is the most significant event for male and female interlinking their emergence of adult hood, it brings many life changes and taken as a start of building a new family. In many countries the fertility of a female especially $1^{\text {st }}$ pregnancy is thought to be important, early marriage is a very old trend, where the age and development of females is not considered. Even it's also been stated in article 16 of universal declaration of human rights that no person should be forced to marry as they have the right to marry with their full consent and at a proper age (Tremayne, 2006). Despite of all national and international laws and steps still many of the individuals are subjected to early marriage. This also cause early termination of education and a disaster of early child bearing thus affecting the female's life in various dimensions (Jacubowski, 2008). There are various factors that contribute to the existence of early marriage which includes male dominancy, parent's ignorance and social pressures. Females are exposed to psychological diseases as they are deprived of the freedom to speak or share. Moreover these females become victims of psychotic disorders like immobility, lack of confidence (Ahmed, 2013). Further we came to know that early married girls are more prone to risk of HIV and other sexually transmitted diseases. (Clark, 2004; Jensen, 2003) There are laws set up by the Pakistani government on forced or early marriages and there is an immense need for the public to follow or act on them as children are main part of society and their childhood shall not be wasted by such incorrect practice of marriage at teenage and they shall not be overloaded with the burdens heavier than their age and physical capability. (Hossain, 2001). Prevalence of child marriage is also associated with poor fertility control and numerous child bearing years hence destroying girl's body. (Raj, 2009) Early married girls are unaware of the proper use of contraceptive which is another reason for their major health problems. Health providers, teachers, social workers are most familiar to the knowledge and consequences of early marriage and they shall play their part to spread this knowledge door to door. (Bearinger, 2007). Many government officials and NGOS are recognizing the need of efforts to be done to make the population aware of every possible outcome of health burdens associated with early marriages (Mathur, 2003).

\section{CONCLUSION}

From the results we conclude that early marriage have caused many health problems. With early marriage there are increased chances for females to be assaulted by health problems either physiologically or psychologically as persona of females is suspended and they are susceptible to psychosocial and physiological health threats. There is immense need of knowledge from biomedical societies, researchers and parents to spread knowledge and education about such issues and steps of awareness shall be taken to teach parents, society and children.

\section{REFERENCES}

- Ahmed, S., Khan, S., Alia, M., \& Noushad, S. (2013). Psychological impact evaluation of early marriages. Int. $\mathrm{j}$. endorsing health sci. res. 1(2).

- Bearinger, L. H., Sieving, R. E., Ferguson, J., \& Sharma, V. (2007). Global perspectives on the sexual and reproductive health of adolescents: patterns, prevention, and potential. The Lancet, 369(9568), 1220-1231.

- Clark, S. (2004). Early Marriage and HIV Risks in Sub-Saharan Africa. Studies in family planning, 35(3), 149160.

- Cook, R. J. (2011). Human rights of women: National and international perspectives. University of Pennsylvania Press.

- Gallo, L. C., Troxel, W. M., Kuller, L. H., Sutton-Tyrrell, K., Edmundowicz, D., \& Matthews, K. A. (2003). Marital status, marital quality, and atherosclerotic burden in postmenopausal women. Psychosomatic Medicine, 65(6), 952-962. 
- Hossain, S., \& Turner, S. (2001). Abduction for forced marriage-rights and remedies in Bangladesh and Pakistan. International Family Law, 1(64), 15-24.

- Jacubowski, N. (2008). Marriage is not a safe place: Heterosexual marriage and HIV-related vulnerability in Indonesia. Culture, health \& sexuality, 10(1), 87-97.

- Jensen, R., \& Thornton, R. (2003). Early female marriage in the developing world. Gender \& Development, 11(2), 9-19.

- Kebede, G., Asnake, M., Alemu, B., \& Deneke, K. (2007). Causes and consequences of early marriage in Amhara Region. In 135th Annual Convention of the American Public Health Association..

- Mathur, S., Greene, M., \& Malhotra, A. (2003). Too young to wed. The lives rights and health of young married girls. International Center for Research on Women, $19 \mathrm{p}$.

- Moore, K. A., \& Waite, L. J. (1981). Marital dissolution, early motherhood and early marriage. Social Forces, 60(1), 20-40.

- Murphy, C. M., \& O'Leary, K. D. (1989). Psychological aggression predicts physical aggression in early marriage. Journal of consulting and clinical psychology, 57(5), 579.

- Murphy, E. M. (2003). "Being born female is dangerous for your health." American Psychologist (58) 3-205.
- Raj, A., Saggurti, N., Balaiah, D., \& Silverman, J. G. (2009). Prevalence of child marriage and its effect on fertility and fertility-control outcomes of young women in India: a crosssectional, observational study. The Lancet, 373(9678), 18831889.

- Santhya, K. G., Ram, U., Acharya, R., Jejeebhoy, S. J., Ram, F., \& Singh, A. (2010). Associations between early marriage and young women's marital and reproductive health outcomes: evidence from India. International Perspectives on Sexual \& Reproductive Health, 36(3).

- Tremayne, S. (2006). Modernity and early marriage in Iran: A view from within. Journal of Middle East Women's Studies, 2(1), 65-94.

- United Nations Children's Fund, the (UNICEF), \& UNICEF. (2005). Early Marriage: A Harmful Traditional Practice, a Statistical Exploration. UNICEF.

- Walker, J. A. (2012). Early Marriage in Africa-Trends, Harmful Effects and Interventions. African journal of reproductive health, 16(2), 231-240. 